\title{
MODELO DE TUTORIA NO ENSINO A DISTÂNCIA EINSTEIN: UM ESTUDO SOBRE O PAPEL E AS COMPETÊNCIAS DO TUTOR
}

\author{
SÃO PAULO/SP JULHO/2018
}

\author{
Kenia Gomes Alcântara - SBIBAE - kenia.goalcantara@einstein.br \\ Sandra Oyafuso Kina - SBIBAE - sandra.kina@einstein.br \\ Felipe Spinelli de Carvalho - SBIBAE - felipe.spinelli@einstein.br
}

Tipo: Investigação Científica (IC)

Natureza: Descrição de Projeto em Andamento

Categoria: Métodos e Tecnologias

Setor Educacional: EDUCAÇÃO SUPERIOR

\begin{abstract}
RESUMO
Uma nova relação com o saber permeada pelo desafio da passagem e convivência de um novo modelo de ensino centrado no aluno e mediado pelo tutor passou a ocupar um lugar de destaque nas políticas dos países mais desenvolvidos nas últimas décadas e atrair a atenção das mais diferentes instituições e empresas, por permitir o acesso à informação de forma assíncrona, o ensino a distância. Esta modalidade de ensino tem um importante papel a desempenhar na atualização de um profissional e desafia os paradigmas do ensino tradicional, já que viabiliza a produção de novos conhecimentos e formas de relacionar-se, até então, desconhecidas. A interação comunicativa, fundamental em qualquer processo educativo, ocupa um espaço vital nesta modalidade, assim como o papel desempenhado pelo tutor. A tutoria é indispensável no acolhimento do aluno em um Ambiente Virtual de Aprendizagem (AVA). Uma tutoria eficiente apresentará ao aluno todos os recursos tecnológicos disponibilizados no AVA como possibilidades pedagógicas para facilitar o seu desenvolvimento da aprendizagem e discutir as práticas, papel e competências do tutor como principal articulador do processo de ensino aprendizagem. Dentro do Ensino a Distância ( $E a D)$ são inúmeros os desafios, um deles diz respeito ao modelo de tutoria a ser adotado. O modelo de tutoria implantado pelo EaD Einstein cuja centralidade está no Programa de Capacitação e Formação de Tutores é integrado por: Processo Seletivo, Prova Técnica, Capacitação Pedagógica do Tutor EaD, Capacitação Técnica do Tutor EaD no AVA, Organização do corpo de tutores e Avaliação do Tutor EaD Einstein. Com a utilização dos dados das pesquisas de satisfação como insumos para a ação de melhoria, em parceria com a Qualidade da Diretoria do Ensino se consegue um grau de participação do tutor que aperfeiçoa o modelo de ensino e aprendizagem, e humaniza a relação tutor-aluno pela ênfase no diálogo e nas mudanças decorrentes do processo da avaliação.
\end{abstract}

Palavras-chave: modelo de tutoria; papel do tutor; avaliação de satisfação da tutoria. 


\section{Introdução}

No Ensino à Distância (EaD), dentro da perspectiva de uma comunicação mais flexível e inteligente, propiciada pelo uso de recursos tecnológicos como forma de motivar o aluno a explorar o conhecimento fora da sala de aula, vem se firmando como proposta inovadora no campo da educação. Nesse contexto, vislumbra-se uma nova relação com o saber permeada pelo desafio da passagem e convivência de um novo modelo de ensino centrado no aluno e mediado pelo tutor. Na legislação brasileira, antes de 2007, não há registros sobre a figura do tutor. Somente nos Referenciais de Qualidade para Educação Superior a Distância o tema foi tratado pela primeira vez. A tutoria a distância atua a partir da instituição, mediando o processo pedagógico junto a estudantes geograficamente distantes, e referenciados aos polos descentralizados de apoio presencial. Sua principal atribuição deste profissional é o esclarecimento de dúvidas, através de fóruns de discussão pela internet, pelo telefone, participação em videoconferências, entre outros, de acordo com o projeto pedagógico. $O$ tutor tem também a responsabilidade de promover espaços de construção coletiva de conhecimento, selecionar material de apoio e sustentação teórica aos conteúdos e, frequentemente, faz parte de suas atribuições participarem dos processos avaliativos de ensino-aprendizagem, junto com os docentes. (REFERENCIAIS DE QUALIDADE PARA EDUCAÇÃO SUPERIOR A DISTÂNCIA, 2007, p.21). Nesse aspecto, as facilidades da evolução tecnológica apresentam-se como potenciais estimuladores do uso de recursos tecnológicos conectados à Internet como ferramenta que favorece a autonomia e a autoaprendizagem, por meio do acesso a informação e comunicação remota. Em um ambiente virtual de aprendizagem (AVA) o aluno busca o conhecimento de forma autônoma e para isso se utiliza das tecnologias colocadas para instrumentalizar o desenvolvimento da sua aprendizagem. Nesse ambiente, para mediar e orientar o processo de construção do conhecimento do aluno existe a figura do Tutor.

\section{Objetivo}

O objetivo deste estudo é apresentar o modelo de tutoria implantado pelo Ensino à Distância $(\mathrm{EaD})$ Einstein e discutir as práticas, papel e competências do tutor como principal articulador do processo de ensino aprendizagem.

\section{O Tutor como Mediador: papel, práticas e competências}

A tutoria é indispensável no acolhimento do aluno em um AVA. Uma tutoria eficiente apresentará ao aluno todos os recursos tecnológicos disponibilizados no AVA e utilizados como possibilidades pedagógicas para facilitar 0 seu percurso no 
desenvolvimento da aprendizagem. Dessa forma, o tutor deve dominar as tecnologias disponibilizadas no AVA e tirar proveito das suas potencialidades promovendo o uso das mesmas de forma complementar. Da mesma forma, o tutor deve conhecer as limitações de cada tecnologia a fim de poder trabalhar as dificuldades e procurar a melhor forma de utilização da mesma. Em um ambiente virtual, segundo Costa, Campos e Santos (2007), existe uma nova forma de interação, onde deixamos de contar com a presença como condição para a realização das práticas educativas. Nesse processo de interação, facilitado pelo tutor, a aprendizagem cooperativa se dá entre os alunos a partir de um espírito de parceria estabelecido entre eles e o tutor na busca do enriquecimento do saber sobre determinado tema de estudo. A tutoria deve utilizar das ferramentas de comunicação mais adequadas para garantir o processo de interlocução com o aluno. É essencial que o tutor estabeleça vínculos de confiança com o aluno para que o mesmo se sinta seguro e motivado a aprender. Para tanto, o tutor, além de habilidades, competências e qualificação adequada deve ter certa dose de sensibilidade para perceber o nível de desenvolvimento do aluno e do grupo de alunos sob sua tutoria. $O$ tutor deve zelar pelo estabelecimento de uma cultura de trabalho colaborativo promovendo a discussão e o compartilhamento de conhecimentos de forma interativa. Moran (2007) diz que "vivemos formas diferentes de comunicação, que expressam múltiplas situações pessoais, interpessoais, grupais e sociais de conhecer, sentir e viver, que são dinâmicas, que vão evoluindo, modificando-se, modificando-nos e modificando os outros". No ambiente virtual o que leva à concretização da aprendizagem como construção colaborativa é o processo de integração e interação do grupo, mediado pela tutoria. Esse processo de relação interpessoal, caracterizado pelo empenho na interação dialógica do grupo, segundo Kratochwill (2009, 4 p.166), "resulta num ganho qualitativo da aprendizagem, tratando os assuntos com mais coerência, fundamentação e apropriação". O tutor na sua função de mediador encontra desafios que o levam a repensar a forma de apresentação dos conteúdos, de criar mecanismos próprios de otimização dos espaços e recursos virtuais, de buscar métodos que facilitem a sistematização do conhecimento e as formas de interagir com o aluno, incluindo a afetividade, a fim de minimizar possíveis dificuldades e limitações apresentadas pelo aluno no desenvolvimento de atividades na modalidade em rede, bem como potencializar as suas qualidades. É importante que o tutor deixe claro a sua presença e que exerça a sua habilidade de levar o aluno a buscar informações de forma cooperativa e colaborativa e a ter postura autônoma no aprimoramento de sua formação. De acordo com essas premissas, a figura do tutor se torna essencial no processo das relações estabelecidas em um AVA, onde numa concepção sócio construtivista, através da educação no formato em rede, os alunos devem desenvolver habilidades fundamentais para o êxito de sua aprendizagem como: iniciativa, autonomia, independência, disciplina, pro atividade, organização, administração do tempo, busca constante por conhecimento, 
empreendedorismo, curiosidade, autoconfiança, automotivação. O desenvolvimento destas habilidades pelo aluno se constitui efetiva no sucesso do mesmo no mundo do trabalho, pois cada vez mais o mercado contemporâneo demanda pessoas com capacidade técnica, domínio das tecnologias digitais, capacidade para interagir socialmente, seja virtual ou presencialmente, mas principalmente capacidade de aprender de forma independente e contínua. Nesse aspecto, a figura do tutor é responsável pela mediação do conhecimento e pela motivação do aluno a buscar estratégias para potencializar o seu aprendizado de forma autônoma. O tutor, além de possuir qualificação para lidar com as técnicas de ensino e tecnologias colocadas à sua disposição, deve ser sensível às diferenças e limitações dos seus alunos. O tutor no processo de ensino-aprendizagem é o mediador que pressupõe relações de interatividade mediadas pelos recursos tecnológicos e que envolvem uma situação de disposição para maior interação possibilitada pela fusão da emissão-recepção de informações e emoções, que resulta não só em uma participação, mas em uma intervenção que se traduz na ampliação do olhar dos sujeitos envolvidos nesse processo. É importante a percepção nessa geração da educação em rede de que a capacitação para lidar com os recursos tecnológicos por si só não garante o sucesso no processo de ensinar e aprender, e de que são necessárias capacidades e habilidades que garantam a qualidade nas relações estabelecidas no processo de interação e as competências pedagógicas.

\section{Modelo de Tutoria do Ensino à Distância Einstein}

A experiência com as disciplinas no Ensino à Distância $(E a D)$ Einstein tem demonstrado que o sistema de tutoria é cada vez mais indispensável ao desenvolvimento com qualidade da modalidade à distância, cabendo ao tutor a responsabilidade de acompanhar as atividades discentes, motivar a permanência no curso e mediar a construção do conhecimento tanto individual como colaborativo, orientando e proporcionando ao aluno condições de uma aprendizagem autônoma. Os tutores do EAD Einstein são profissionais da saúde ou de áreas correlatas aos cursos oferecidos, colaboradores da Sociedade Beneficente Israelita Brasileira Albert Einstein (SBIBAE), selecionados a partir de critérios previamente definidos e capacitados pela equipe EAD Einstein para atuar em cursos a distância, no ambiente virtual de aprendizagem (AVA). Neste sentido, o EaD Einstein vem investindo na implantação de um sistema tutorial que seja realmente eficaz e eficiente, adequando-o ao perfil do seu aluno em uma rica troca de saberes, capacitando os tutores para que possam apoiar e promover o crescimento do aluno em cada uma das etapas do processo de aprendizagem e ouvindo deles as experiências e propostas de mudanças, de modo a construir um modelo próprio e ao mesmo tempo, desenvolver ações para aperfeiçoar o sistema de EaD Eisntein, que 
pretende ser objeto de constantes reflexões e de avaliação. Os tutores participam ativamente da prática pedagógica e são supervisionados pelos autores dos cursos e equipe de suporte à tutoria, que realizam a gestão pedagógica do processo de desenvolvimento da disciplina, do planejamento à avaliação, além de contribuir na identificação e busca de soluções para as dificuldades e problemas enfrentados pelos alunos, colaborando assim na conquista da sua autonomia. Os tutores atuam como mediadores e facilitadores do processo pedagógico junto aos alunos, norteando as aprendizagens individuais, respondendo e moderando as dúvidas, orientando o processo de aprendizagem, analisando as interações, gerenciando a comunicação e mediando a utilização e manejo de equipamentos e recursos. O atendimento ao aluno é individualizado, sendo realizado via AVA, através do qual responde as dúvidas em até 24 horas. Para tanto, são capacitados para que conheçam as funcionalidades, o AVA e o material didático, a fim de auxiliarem o aluno no desenvolvimento de suas atividades acadêmicas, fomentando o hábito de estudos e pesquisa, esclarecendo dúvidas e orientando sobre o uso das tecnologias disponíveis. A capacitação e a atualização dos tutores EaD Einstein são consideradas um fator de destaque para o alcance dos resultados esperados, tanto que existe uma multiplicidade de diretrizes e ações promovidas e previstas pelo Plano de Desenvolvimento Institucional (PDI) direcionadas à melhoria da ação pedagógica e geração de conhecimento. O Programa de Capacitação de Tutores contempla três dimensões previstas nos Referenciais de Qualidade para a Educação Superior a Distância (MEC, 2007): capacitação no domínio específico do conteúdo; em mídias de comunicação e em fundamentos da EaD e no modelo de tutoria. Assim, o Programa promove cursos levando em conta a necessidade de se preparar recursos humanos para usar pedagogicamente as tecnologias no apoio à aprendizagem, mas sempre considerando que a adoção de modernos instrumentos em velhas práticas educacionais não é garantia de uma nova educação. Esse programa de capacitação integra as seguintes ações:

4.1. Processo Seletivo - os critérios de seleção dos tutores foram definidos em parceria com os Recursos Humanos Einstein. Os candidatos à tutoria são selecionados pela Equipe EAD Einstein e validados pelos Autores do Curso, devendo ter seu curriculum vitae analisado, de modo a serem comprovados: curso de especialização nas áreas e subáreas dos módulos que vai tutorar; profissionais que em seu Plano de Desenvolvimento Interno (PDI) informaram o interesse em atuar na área de ensino; 1 ano de atuação na instituição como profissional da saúde ou de área correlata ao curso oferecido e ter obtido no consenso da última avaliação de competências institucional no mínimo o resultado: Atende (AT). Além desses critérios, os tutores devem ter disponibilidade de tempo para acompanhar o trabalho das turmas nos módulos e realizar as atividades que lhe forem demandadas. 
4.2. Prova Técnica - todos os candidatos que cumprirem os critérios acima, passam por uma prova técnica e para prosseguirem no processo precisam de uma nota mínima de 7,0 para sua aprovação. Os reprovados em prova técnica só poderão concorrer em um prazo de 3 meses.

4.3. Capacitação Pedagógica do Tutor EaD - curso na modalidade blended learning, através do qual os tutores conhecem as diretrizes do EaD Einstein, assim como suas atribuições e responsabilidades; recebem os Guias e tutoriais do AVA, tiram dúvidas, conhecem a equipe da Tutoria (encontro presencial de $2 \mathrm{H}$ ). As principais orientações desta etapa são: dedicar 1 hora do dia durante o período do curso (assiduidade na plataforma);sanar as dúvidas dos alunos dentro de 24 horas;participação nos fóruns (tutoria proativa/inserir nota de participação);entender as maiores dificuldades dos alunos, capacidade de exemplificação e problematização de acordo com o perfil de cada aluno;incentivar a participação e compartilhamento de ideias e dúvidas;evitar evasão de alunos;correção das atividades e realizar Web Conferência. Será oferecido um curso de Capacitação de $30 \mathrm{H}(\mathrm{EaD})$, dividido em quatro módulos abordando: Fundamentos do EAD, Gestão do EAD, Papel do Tutor do EAD e Referências de Qualidade em EAD.

\subsection{Capacitação Técnica do Tutor EaD no Ambiente Virtual de Aprendizagem}

(AVA) - compreende um treinamento individual e/ou coletivo na Sala de Informática, no qual os tutores recebem capacitação pedagógica e tecnológica para uso das funcionalidades do AVA e uma senha de acesso ao ambiente, previamente agendados, com o suporte técnico para sanar dúvidas

4.5. Organização do corpo de tutores - As informações sobre os tutores são registradas em um banco de dados, o qual deve possibilitar a futura seleção de tutores dos mesmos com base nos seguintes critérios Técnicos (por área e subárea de conhecimento; por disciplinas tutoradas e por tipo de curso tutorado) e Gestão de Pessoas: por situação funcional (nível do cargo); por avaliação de desempenho (nota de avalição de desempenho). Os tutores serão alocados nos cursos, contemplando a área de formação acadêmica, considerada a área do curso ou o módulo a ser tutorado e nível funcional superior ao da turma a ser tutorada e habilidades e experiências específicas de uma atividade profissional demandada pelo módulo ou curso tutorado.

4.6. Avaliação do Tutor EaD Einstein - compreende em o tutor ser avaliado baseado em suas responsabilidades, entregas (cumprimento do cronograma do curso), satisfação do aluno e à taxa de evasão. A equipe $\mathrm{EaD}$ faz encontros presenciais para realizar o Feedback da Tutoria e apresenta a nota de avaliação de desempenho do tutor, esta nota está vinculada à taxa de evasão da turma tutorada, avaliação de satisfação e ao 
pagamento do bônus desempenho do Tutor, este será proporcional à média final.

\section{Pesquisa de Satisfação do Aluno}

Para avaliar o nível de satisfação dos alunos nos cursos EaD Einstein ofertados, realizamos ao término de cada curso ou disciplina uma Avaliação de Satisfação Geral EaD Einstein. Nosso foco principal é realizar um diagnóstico e propor estratégias de melhorias em seu Plano de Gestão. Fizemos o levantamento das avaliações dos cursos ofertados no período de janeiro e fevereiro de 2018, totalizando 50 cursos. A avaliação contou com um total de 511 alunos matriculados em cursos de atualização na área da Saúde do EaD Einstein e teve uma amostra de 275 alunos respondentes que compôs uma representatividade de $53,8 \%$ do total. Destes alunos, 386 foram Aprovados (60 alunos aprovados após Recuperação), 93 Reprovados e 33 Evadidos. Os dados foram coletados por meio da plataforma de Ensino EaD Einstein, onde o aluno ao finalizar sua Atividade Individual, tem acesso à Avaliação de Satisfação Geral com base nos seguintes critérios: Satisfação Geral (satisfação com o curso em geral), Net Promoter Score (NPS), que se concentra em uma única pergunta sobre a indicação do curso (mensura a satisfação e lealdade dos alunos), Conteúdo, Estratégias de Ensino, Plataforma, Professor-tutor, Atendimento e Suporte e Processo de Inscrição.

O Quadro 1 descreve os Critérios Gerais da Avaliaçẫo de Satisf açẫo.

\begin{tabular}{|c|c|}
\hline Critérios Avaliação & Média Geral \\
\hline $\begin{array}{l}\text { NPS (Indicaçẫo) - *Em uma escala de } 0 \text { a } 10 \text {, quanto você } \\
\text { indicaria este curso para um amigo ou familiar? Quanto } \\
\text { mais disposto está para recomendar, mais se ap roxima ao } \\
10 \text { e quanto menos disposto, mais se aproxima ao } 0 \text {. } \\
\text { O NPS é calculad o da seguinte forma: Net Promoter } \\
\text { Score (NPS) = \% CLIENTE S PROMOTORE S - } \\
\% \text { CLIENTES DETRATORE S = \%NPS } \\
\text { Notas de - } 100 \text { a 0 = Zona crítica } \\
\text { Notas de } 1 \text { a } 49=\text { Zona de Aperf eiçoamento } \\
\text { Notas de } 50 \text { a } 74 \text { = Zona de Qualidade } \\
\text { Notas de } 75 \text { a } 100 \text { = Zona de Excelência }\end{array}$ & 71 \\
\hline $\begin{array}{l}\text { Satisfação Geral - De forma geral, levando tudo em } \\
\text { consideraçẫo, como está a satisfaçấo como curso que } \\
\text { acabou de realizar? }\end{array}$ & 8,99 \\
\hline Conteúdo & 8,99 \\
\hline Estratégias de Ensino & 8,96 \\
\hline Plataforma & 8,99 \\
\hline Professor-tutor & 9,33 \\
\hline Atendimento e Suporte & 8,64 \\
\hline Processo de inscrição & 9,36 \\
\hline
\end{tabular}


- Quadro 2 descreve os Critérios de Avaliação da Mediaçăo Pedagógica

(Estratégias de Ensino).

\begin{tabular}{|c|c|}
\hline Critérios Avaliação Estratégias de Ensino & Média \\
\hline $\begin{array}{l}\text { 1. VIDEOS (vídeos de especialistas, procedimentos e/ou } \\
\text { vídeo aula) - para consolidaçăo do aprendizado }\end{array}$ & 9,04 \\
\hline $\begin{array}{l}\text { 2. CONTEÜDO INTERATIVO - conteúdo teórico do curso } \\
\text { com ilustraçôes e animaçôes, glossário, referência } \\
\text { bibliográfica e questôes para reflexăo }\end{array}$ & 9,01 \\
\hline $\begin{array}{l}\text { 3. CADERNO DE ATIVIDADES - Momento de Prática e } \\
\text { Reflexăo, análise de situaçăo problema e exercícios com } \\
\text { foco na aplicaçăo prática }\end{array}$ & 9,24 \\
\hline $\begin{array}{l}\text { 4. FORUM DE DISCUSSÄO- voltado para esclarecimentos } \\
\text { de dúvidas e troca de experiências }\end{array}$ & 9,01 \\
\hline $\begin{array}{l}\text { 5. ENCONTRO VIRTUAL - web conferência realizada com } \\
\text { o professor-tutor para esclarecimentos de dúvidas e troca } \\
\text { de experiências }\end{array}$ & 8,49 \\
\hline Média Geral Estratégias de Ensino & 8,95 \\
\hline
\end{tabular}

O Quadro 3 descreve os Critérios de Avaliaçẩo da Mediaçẫo Pedagógica (Professortutor).

\begin{tabular}{|l|c|}
\hline \multicolumn{1}{|c|}{ Critérios Avaliação Professor-tutor } & Média \\
\hline 1. Domínio do conteú do e clareza na comunicaçấo & $\mathbf{9 , 4 9}$ \\
\hline $\begin{array}{l}\text { 2. Incentivo para troca de experiência e informaçôes para } \\
\text { consolidaçấo do apren dizado }\end{array}$ & $\mathbf{9 , 3 2}$ \\
\hline $\begin{array}{l}\text { 3. Aprofundamento das discussôes nos fóruns, com } \\
\text { exemplos e sugestôes de novas leituras }\end{array}$ & $\mathbf{9 , 1 5}$ \\
\hline $\begin{array}{l}\text { 4. Disponibilidade para esclarecimento de dúvidas e retorno } \\
\text { às mensagens }\end{array}$ & $\mathbf{9 , 3 8}$ \\
\hline Média Geral Professor-tutor & $\mathbf{9 , 3 2}$ \\
\hline
\end{tabular}

\section{Pesquisa de Satisfação do Tutor}

Para avaliar o nível de satisfação dos tutores em relação ao suporte da equipe EaD durante a tutoria, realizamos ao término de cada ano uma Avaliação de Satisfação Geral EaD Einstein. Nosso foco principal é realizar um diagnóstico e propor estratégias de melhorias em nosso processo de Atendimento e Operação EaD. Foram enviadas 65 convites e obteve-se taxa de resposta de $46 \%$ no período de 29/11/17 a 12/12/2017. 
Q Quadro 4 descreve os Critérios de Avaliação do Atendimento e Operação EaD.

\begin{tabular}{|c|c|}
\hline Critérios Avalią̧ão & Média Geral \\
\hline $\begin{array}{l}\text { NPS (Indicação)- "Em uma escala de } 0 \text { a } 10 \text {, quanto você indicaria } \\
\text { este curso para um amigo ou familiar? Quanto mais disposto está } \\
\text { para recomendar, mais se aproxima ao } 10 \text { e quanto menos } \\
\text { disposto, mais se aproxima ao } 0 \text {. O NPS é calculado da seguinte } \\
\text { forma: Net Promoter Score (NPS) = \% CLIENTES } \\
\text { PROMOTORES - \% CLIENTES DETRATORES = \%oNPS } \\
\text { Notas de - } 100 \text { a } 0 \text { = Zona crítica } \\
\text { Notas de } 1 \text { a } 49=\text { Zona de Aperfeiçoamento } \\
\text { Notas de } 50 \text { a } 74=\text { Zona de Qualidade } \\
\text { Notas de } 75 \text { a } 100=\text { Zona de Excelência }\end{array}$ & 41 \\
\hline $\begin{array}{l}\text { Satisaçäo Geral- De forma geral, levando tudo em consideraçăo, } \\
\text { como está a satisfaçẫo com o curso que acabou de realizar? }\end{array}$ & 7,9 \\
\hline $\begin{array}{l}\text { Recursos e tecnologias disponíveis para excelência do seu } \\
\text { trabalho }\end{array}$ & 8,8 \\
\hline Suporte administrativo para desenvol vi mento do seu trabalho & 8,7 \\
\hline $\begin{array}{l}\text { Apoio da Equipe EaDe efetividade da resoluçăo de problemas } \\
\text { técnicos e com alunos }\end{array}$ & 9,0 \\
\hline $\begin{array}{l}\text { Atençăa e cordialidade da Equipe EaD no direcionamento das } \\
\text { atividades }\end{array}$ & 9,4 \\
\hline $\begin{array}{l}\text { Compartilhamento de infor maçóes e direcionamentos } \\
\text { regulares para o desenvol vi mento do seu trabalho }\end{array}$ & 8,5 \\
\hline Sistemática de feedback do desempenho geral dos cursos & 7,0 \\
\hline Oportunidades para atividades de apri moramento profissional & 7,7 \\
\hline Acessoe uso do Ambiente Virtual de Aprendizagem & 8,6 \\
\hline $\begin{array}{l}\text { Facilidade no acompanhamento de tarefas e correçăo de } \\
\text { atividades }\end{array}$ & 8,4 \\
\hline $\begin{array}{l}\text { Alinhamentos e integraçóes com o autor para entendi mento e } \\
\text { melhoria do curso }\end{array}$ & 8,3 \\
\hline Reconheci mento geral pelo seu trabalho & 7,8 \\
\hline $\begin{array}{l}\text { A. Equipe do EaD respondeu prontamente todas as ligaçóese } \\
\text { e-mails nos prazos acordados }\end{array}$ & 9,0 \\
\hline Mnhas ideias e necessidades são respeitadas e discutidas & 8,4 \\
\hline $\begin{array}{l}\text { Sinto que o método de ensino utilizado em nossos cursos } \\
\text { a distância per mite o completo aprendizado aos alunos }\end{array}$ & 9,3 \\
\hline
\end{tabular}

\section{Considerações Finais}

A tutoria e as competências requeridas pelo tutor na perspectiva de uma comunicação mais flexível e eficiente, confirma a necessidade de se continuar produzindo reflexões e ações nesse tema, sendo necessário revisitá-lo sempre. A experiência do EaD Einstein demonstra que o modelo de tutoria deve ser desenvolvido com a sua realidade. Nesse sentido é oportuno dizer que não existe um modelo ideal para a tutoria, mas uma experiência com êxito no EaD passa pela atenção com o investimento em formação da equipe, incluindo a capacitação de tutores. Os dados da pesquisa mostram que a mediação pedagógica é uma dimensão sensível do processo. Percebe-se no caso apresentado que o tutor demonstra competência em itens fundamentais como domínio de conteúdo bem como nos aspectos de relacionamento, mas fatores administrativos e de infraestrutura podem estar dificultando o nível de satisfação geral com a dimensão. Pesa ainda, a persistência na falta de posicionamento de uma parcela dos alunos 
respondentes. Os dados da pesquisa mostram também que nosso suporte de maneira geral atende as expectativas dos tutores, mas nossa sistemática de feedback do desempenho geral dos cursos necessitou de uma reavaliação e hoje é realizada com $100 \%$ dos tutores e não apenas nos cursos críticos. Concluímos que estamos no caminho certo ao perseguirmos um modelo próprio de tutoria desenhado em competências e que somente o investimento contínuo em tecnologias, capacitação, avaliação e feedback produzirão os melhores resultados.

\section{Referências Bibliográficas}

CAMPOS, F.C.A., COSTA, R.M.E e SANTOS, N. Fundamentos da educação a distância, mídias e ambientes virtuais. Juiz de Fora: Editar, 2007

KRATOCHWILL, S. Avaliação da aprendizagem em uma perspectiva dialógica a partir do fórum on-line. In: Aprendizagem em ambientes virtuais. Porto Alegre: Mediação, 2009.

MINISTÉRIO DA EDUCAÇÃO (Brasil). Referenciais de qualidade para a educação superior a distância. Brasília, DF: SEED/MEC, 2007. Disponível em http://portal.mec.gov.br/seed/arquivos/pdf/legislacao/refEaD1.pdf. Acesso em: 18 de maio. 2018.

MORAN, José Manuel. Desafios na comunicação pessoal. As muitas formas de comunicar-nos. São Paulo: Paulinas, 2007. 